\title{
Formulation of pyridoxine hydrochloride sustained release capsules: Effect of propylene glycol co-solvent on the in vitro release
}

\author{
V. I. Onyishi, S. A. Chime* and C. V. Adibe \\ Department of Pharmaceutical Technology and Industrial Pharmacy, University of Nigeria, Nsukka 410001, Nigeria.
}

Accepted 15 April, 2013

\begin{abstract}
The objectives of the present study were to formulate sustained release pyridoxine hydrochloride capsules and to study the effect of propylene glycol co-solvents on the in vitro properties of the capsules. All batches of formulations were made with fixed concentrations of binder-disintegrants, diluents and equal load of active pharmaceutical ingredient. The granules were prepared by wet granulation using propylene glycol water co-solvent as the wetting agent, sodium carboxymethylcellulose (SCMC) and maize starch were used as binder-disintegrant and kaolin was used as the diluents. The micromeritic properties of the granules were analysed by direct and indirect methods. The granules were encapsulated in hard gelatin capsule No. 1. The capsule weight uniformity, disintegration time and drug content were determined. In vitro dissolution test was performed in $0.1 \mathrm{~N}$ $\mathrm{HCl}$, simulated gastric fluid (SGF, pH 1.2) and simulated intestinal fluid (SIF, pH 7.2). The results showed that the particles size of granules ranged from 245 to $259 \mu \mathrm{m}$ and had good flowability. The capsules complied with British Pharmacopoeia (BP) requirement for capsule weight uniformity. The drug content was within 90 to $110 \%$ of the average values. The results of in vitro drug release in SGF $(\mathrm{pH}, 1.2)$ showed that the release of pyridoxine hydrochloride was very slow and was significantly $(P<0.05)$ lower than the release in $0.1 \mathrm{~N} \mathrm{HCl}$ and in SIF $(\mathrm{pH}, 7.2)$, respectively. Therefore, pyridoxine hydrochloride sustained release capsules could be formulated with kaolin as the diluent and propylene glycol co-solvent as the moistening agent in order to reduce the frequency of administration of this drug and improve patient compliance.
\end{abstract}

Key words: Pyridoxine hydrochloride, sustained release, capsules, particle size analysis.

\section{INTRODUCTION}

Over the years, much work has been carried out to improve patient compliance of conventional oral and parenteral single dosage forms meant for repeated administration (Ravi-Kumar, 2000; Wissing et al., 2004; Mathew and Devi, 2007; Rhee et al., 2007; Jia et al., 2008; Kim et al., 2010). This has led to the development of effective sustained release dosage forms. Among all the factors that make for an ideal therapy, the most difficult to achieve is maintaining serum concentrations of drugs at therapeutic levels for a long period of time. This is usually done by repeated administration and poses serious problem of patient compliance. Sustained release dosage forms are preparations with controlled rate of absorption of drug into the body, which is achieved mainly by controlling the dissolution rate of the formulations (Umeyor et al., 2012). Sustained release dosage forms provide an initial release of drug sufficient to provide a therapeutic dose soon after administration, and then a gradual release over an extended period. The rationale for the controlled delivery of drugs is to promote therapeutic 
benefits, while at the same time minimizing toxic effects (Sinko, 2006). Capsules and tablets are the most common oral dosage forms. These formulations differ from each other in that material in capsules is less impacted than in compressed tablets. Once a capsule dissolves, the contents generally disperse quickly (Welling, 2002). In the formulation of capsules, particle, flowability is of paramount importance (Welling, 2002). The flow of powder during manufacturing dictates the quality of the product in terms of weight and content uniformity of the capsules (Aulton, 2007). The measurement of the flow properties of powders is essential before capsule filling, because variation in particle flow will automatically cause variation in capsule weight and active ingredient variation. The flow property of bulk material results from the cohesive forces acting on individual particles such as van der Waals, electrostatic, surface tension, interlocking, and friction (Aulton, 2007).

Pyridoxine is a water-soluble vitamin involved mainly in amino acid metabolism, and is also involved in carbohydrate and fat metabolism. It is required for the formation of haemoglobin and is usually given as the hydrochloride, although other salts such as the citrate, oxoglurate, phosphate, and phosphoserinate, have also been used. Pyridoxine is used in the treatment and prevention of pyridoxine deficiency states (Sean, 2011). It is usually given orally, the preferred route, but may also be given by the subcutaneous, intramuscular, or intravenous routes (Sean, 2009). It is used to treat certain metabolic disorders such as homocystinuria or primary hyperoxaluria, seizures due to hereditary syndromes of pyridoxine deficiency and premenstrual syndrome. The aim of this work was to formulate pyridoxine sustained release capsules and to study the effect of propylene glycol co-solvent on the in vitro release.

\section{MATERIALS AND METHODS}

The following materials were used: pyridoxine hydrochloride (BDH Chemicals Ltd., England), sorbic acid, sodium carboxymethylcellulose (SCMC), maize starch, ferric chloride, hydrochloric acid, sodium hydroxide, sodium chloride and monobasic potassium phosphate, sodium benzoate (BDH Chemicals Ltd., England), kaolin, propylene glycol (Merck, Darmstadt, Germany). All other reagents and solvents were of analytical grade and were used as supplied.

\section{Preparation of granules}

The granules were prepared by wet granulation using propylene glycol water co-solvent as the wetting agent; details of formulation are shown in Table 1. SCMC and maize starch were used as binder-disintegrant, sorbic acid and sodium benzoate were used as the preservative and kaolin was used as the diluents. The powders were mixed for $10 \mathrm{~min}$ in a tumbler mixer (Rotor mixer S42P43, Forster Equipment Co. Ltd., England) together with pyridoxine hydrochloride. The powder mixtures were moistened with the appropriate amount of the wetting agent and were triturated in a mortar to a homogenous mix. The homogeneous wet mass was then screened through a $1.7 \mathrm{~mm}$ sieve and the wet granules were dried in a hot air oven at $55^{\circ} \mathrm{C}$ for $1 \mathrm{~h}$ (Memmer, U25, Western Germany). Thereafter, the dried granules were screened through a $1.0 \mathrm{~mm}$ sieve.

\section{Evaluation of granules}

\section{Particle size distribution}

The particle size of the granules was determined using nest of sieves (numbers 16, 52, 100 and 200) arranged in descending order of aperture size with a pan collector underneath. Eighteen grams quantity of each batch of granulations was accurately weighed using an electronic weighing balance (Ohaus Adventurer, SNR - 1121 R53860, China), and transferred to the top most of a series of sieves. The sieve arrangement was transferred to an Endecott mechanical sieve shaker (Endecott 1 MK 11, 6315, London, England) and was shaken for $5 \mathrm{~min}$. At the end of $5 \mathrm{~min}$, the fraction of powder retained by each sieve was weighed. Three determinations were carried out and the mean particle diameter $\left(d_{a v}\right)$ was determined using the relation (Ansel et al., 2007; Okoye et al., 2012):

$$
\mathrm{d}_{\mathrm{av}}=\frac{\left.\sum \text { (Percentage powder retained } \mathrm{x} \text { Mean aperture size }\right)}{100}
$$

\section{Bulk and tapped densities}

A $25 \mathrm{~g}$ quantity of each granule sample was placed in a $100 \mathrm{ml}$ measuring cylinder and the volume occupied by the sample was noted as the bulk volume. The bulk density $\left(\ell_{B}\right)$ was calculated using the equation:

$$
\text { Bulk density }\left(E_{\mathrm{B}}\right)=\frac{\text { Masz ofpowder }(\mathrm{M})}{\text { Eulk volume ofpowder }\left(\mathrm{V}_{\mathrm{B}}\right)}
$$

The tapped volume was determined by tapping the cylinder on a wooden flat surface from a height of 1 inch at $2 \mathrm{~s}$ interval until there was no significant change in volume reduction (Aulton, 2007; Ngwuluka et al., 2010; Chime et al., 2012). The volume occupied by the sample was then recorded as the tapped volume. The tapped density $\left(\ell_{T}\right)$ was calculated using the formula:

$$
\text { Tapped density }\left(\ell_{\mathrm{T}}\right)=\frac{\text { Mass ofpowder }(\mathrm{M})}{\text { Tapped volume of pewder }\left(V_{\mathrm{T}}\right)}
$$

\section{Flow rate and angle of repose}

A $25 \mathrm{~g}$ quantity of pyridoxine hydrochloride granules was weighed out and gradually placed into the funnel clamped onto a retort stand; the funnel orifice was closed with a shutter. The time taken for all the granules to flow through the orifice was noted. The flow rate was calculated using Equation 4:

Flow rate $(w)=\frac{\text { Mass of powder }(\mathrm{g})}{\text { Time of flow }(\mathrm{s})}$

The angle of repose was determined by measuring the height of heap of powder formed using a cathetometer; the radius was gotten by dividing the diameter by two. Angle of repose $(\Theta)$ for each granule 
Table 1. Composition of pyridoxine hydrochloride sustained release capsules.

\begin{tabular}{lccccc}
\hline \multirow{2}{*}{ Ingredient } & \multicolumn{5}{c}{ Weight/capsule (mg) } \\
\cline { 2 - 6 } & F1 & F2 & F3 & F4 & F5 \\
\hline Pyridoxine hydrochloride $(\mathrm{mg})$ & 50.00 & 50.00 & 50.00 & 50.00 & 50.00 \\
SCMC $(\mathrm{mg})$ & 50.00 & 50.00 & 50.00 & 50.00 & 50.00 \\
Maize starch (mg) & 25.00 & 25.00 & 25.00 & 25.00 & 25.00 \\
Sorbic acid (mg) & 1.25 & 1.25 & 1.25 & 1.25 & 1.25 \\
Sodium benzoate (mg) & 1.25 & 1.25 & 1.25 & 1.25 & 1.25 \\
Propylene glycol (ml) & 1.00 & 2.00 & 3.00 & 4.00 & 5.00 \\
Magnesium stearate (1\%) & 2.50 & 2.50 & 2.50 & 2.50 & 2.50 \\
Kaolin q.s (mg) & 250.00 & 250.00 & 250.00 & 250.00 & 250.00 \\
\hline
\end{tabular}

SCMC: Sodium carboxymethylcellulose.

granule sample was calculated using the formula:

$\theta=\tan ^{-1} \frac{\text { heighr of powder heap }}{\text { radius of powder }}$

\section{Compressibility index and Hausner's quotient}

Carr's compressibility index (\%) of the granules was obtained using the formula:

$$
\text { Carr'sindex }(\%)=\frac{\ell_{\mathrm{T}}-\ell_{\mathrm{E}}}{\ell_{\mathrm{T}}} \times 100
$$

While Hausner's ratio was obtained using Equation 5:

Hausner's ratio $=\frac{\ell_{\mathrm{T}}}{\ell_{\mathrm{B}}}$

where $\ell_{\mathrm{T}}$ and $\ell_{\mathrm{B}}$ are tapped and bulk densities, respectively.

\section{Preparation of capsules}

The granules were treated with magnesium stearate as shown in Table 1, and then filled manually using capsule shell No 1.

\section{Evaluation of capsules}

\section{Weight uniformity}

Twenty capsules were selected from each batch, and weighed individually, the contents of the capsule were emptied and weighed and also the empty capsule shell was also weighed. The mean standard deviation and percentage coefficient of variation of the mean weight was calculated.

\section{Disintegration time test}

Disintegration time test was conducted using an Erweka ZT 120 basket and rack assembly. Distilled water maintained at $37.0 \pm$ $1.0^{\circ} \mathrm{C}$ was used as the disintegration medium. Ten capsules from each batch were used for the test and the procedure being as stipulated in the British Pharmacopoeia (BP, 2009) for disintegration time of capsules.

\section{Content of active ingredient}

Beer's calibration curve for pyridoxine hydrochloride was obtained at a concentration range of 2.0 to $10.0 \mathrm{mg} \%$ in $0.1 \mathrm{~N} \mathrm{HCl}$ at a predetermined wavelength of $450 \mathrm{~nm}$. Twenty capsules were randomly selected from each batch of the tablets. The capsules were emptied and the content weighed together. An amount equivalent to the average weight of the capsule was weighed out in an analytical balance. The weighed amount was dispersed in the medium and was filtered. Two drops of ferric chloride was added to an aliquot of the filtrate and was assayed using spectrophotometer (Pye Unicam SP6 450 UV/VIS spectrophotometer, England) at $450 \mathrm{~nm}$. The concentration of the drug in each capsule was calculated using the absorbance readings.

\section{In vitro release studies}

Beer's plot was obtained for pyridoxine hydrochloride in $0.1 \mathrm{~N} \mathrm{HCl}$, simulated gastric fluid (SGF, $\mathrm{pH}$ 1.2) and simulated intestinal fluid (SIF, pH 7.2), respectively at a concentration range of 2 to $10 \mathrm{mg} \%$. USP paddle method was adopted in the study. The dissolution medium consisted of $900 \mathrm{ml}$ of freshly prepared medium maintained at $37 \pm 1^{\circ} \mathrm{C}$. A capsule from each batch was placed inside a tightly secured basket and the basket was placed in the bottom of the beaker. The paddle was rotated at $100 \mathrm{rpm}$. About $5 \mathrm{ml}$ was withdrawn from the dissolution medium at $0.5,1.0,1.5,2.0,2.5$, $3.0,3.5,4.0,4.5$ and $5.0 \mathrm{~h}$, and was filtered with a non adsorbent filter paper (Whatman No. 1). Two drops of ferric chloride was added to an aliquot of the filtrate and assayed using spectrophotometer (Pye Unicam SP6 450 UV/VIS spectrophotometer, England) at predetermined wavelengths of $450 \mathrm{~nm}$ in $0.1 \mathrm{~N} \mathrm{HCl}$ and SGF and $296 \mathrm{~nm}$ in SIF. An equal volume of the withdrawn sample was replaced with a fresh medium to maintain sink condition in each case. The amount of drug released at each time interval was determined with reference to the standard Beer's plot for each drug. The experiment was repeated two times for each sample and the mean was calculated.

\section{In vitro release kinetics}

The dissolution data for the capsules were analysed to determine the in vitro release kinetic mechanism using three kinetic models including the first order equation, Higuchi square root equation and Ritger-Peppas empirical model. Drug release is said to be of first- 
order if it obeys the following equation:

$\ln Q_{t}=\ln Q_{0}-K_{1} t$

where $Q_{t}$ is the amount of drug released or dissolved at time $t, Q_{0}$ is amount of drug released or dissolved at time $t=0, \mathrm{k}_{1}$ is first-order release rate constant (Singh et al., 2011).

According to Higuchi relationship, the amount of drug released per unit surface area is proportional to the square root of time. This equation explains diffusion release rate as indicated below:

$Q_{t}=K_{H} t^{1 / 2}$

where $\mathrm{k}_{\mathrm{H}}$ is Higuchi rate constant, $\mathrm{Q}_{\mathrm{t}}$ has same meaning as defined earlier (Singh et al., 2011). The integral form of Higuchi equation is employed in seeking to establish whether mixed order release kinetics exists. Diffusion controlled process is dominant where the log-log plot of the integral form of Higuchi equation approaches 0.5 (Ofoefule and Chukwu, 2002).

Ritger and Peppas (1987a,b) developed an empirical equation to analyze both Fickian and non-Fickian release of drug from swelling as well as non-swelling polymeric delivery systems. The equation is represented as:

$\mathrm{M}_{\mathrm{t}} / \mathrm{M}_{\alpha}=\mathrm{Kt}^{\mathrm{n}}$

where $M_{t} / M_{\alpha}$ is the fraction of drug released at time $t, n$ is diffusion exponent indicative of the mechanism of transport of drug through the polymer, $K$ is the kinetic constant (having units of $t^{-n}$ ) incorporating structural and geometric characteristics of the delivery system. The release exponent $n \leq 0.5$ for Fickian diffusion release from slab (swellable matrix), $0.5<\mathrm{n}<1.0$ for non-Fickian release (anomalous), this means that drug release followed both diffusion and erosion controlled mechanisms and $n=1$ for zero order release, that is, drug release is independent of time (Ritger and Peppas, 1987a, b).

\section{Statistical and data analysis}

Data were analyzed using Statistical Package for Social Sciences (SPSS) Version 16.0 (SPSS Inc. Chicago, IL.USA). All values were expressed as mean \pm standard deviation (SD). Data were analysed by one-way analysis of variance (ANOVA). Differences between means were assessed using student's t-test. $P<0.05$ was considered statistically significant.

\section{RESULTS AND DISCUSSION}

\section{Granule properties}

\section{Particle size of granules}

The results of particle size of pyridoxine granules are shown in Table 2. From the results, the particle size ranged from 245 to $259 \mu \mathrm{m}$. As the dimensions of particles increase and the particles change in nature, the forces acting on them change. Fine powder particles less than $100 \mu \mathrm{m}$ in diameter are acted upon primarily by surface forces, while particles above $1000 \mu \mathrm{m}$ in diameter are governed by gravitational forces (Fukumori and Ichikawa, 2002). Therefore, the balance of interactive forces determines powder behavior. With relatively small particles, the flow through an orifice may be restricted, because the cohesive forces between the particles are of the same magnitude as gravitational forces. Large particles however with respect to the orifice through which it has to flow can cause arching that can block flow from hopper to die cavity (Fukumori and Ichikawa, 2002). The flowability of powders decreases as the shapes of particles become more irregular. Efforts to relate various shape factors to powder and their surfaces such as size, shape, surface morphology, packing conditions, and interparticle forces must therefore be considered. To make the situation more complex, the interparticle forces can be of a number of types: mechanical forces, surface tension, electrostatic forces, van der Waals forces, solidbridge forces, or plastic welding forces; none of these can be readily quantified (Fukumori and Ichikawa, 2002). The results therefore showed that the granules were within limits for good flow of powders as shown in Table 2.

\section{Flow properties}

The results of the flow properties of pyridoxine hydrochloride granules are shown in Table 2 . The results of loosed densities (bulk and tapped densities) showed that the granules had reduced densities and hence had good flowability. The flow of powder during manufacturing dictates the quality of the product in terms of weight and content uniformity of the capsules (Lachman et al., 1990). The measurement of the flow properties of powders is essential before capsule filling because variation in particle flow will automatically cause variation in capsule weight and active ingredient variation. The flow property of bulk material results from the cohesive forces acting on individual particles such as van der Waals, electrostatic, surface tension, interlocking, and friction (Lachman et al., 1990). Bulk and tapped densities are important, because they are used as an indirect method of assessing powder flowability. Hausner's ratio, determines the degree of interparticulate friction and values $\leq 1.25$ indicates good flow, while Hausner's ratio > 1.25 indicates poor flow. The results indicated that Hausner's ratio ranged from 1.10 to 1.22; therefore, they were within the limits for good powder fluidity. Carr's compressibility index also reveals the degree of interparticulate friction and values between 5 and 17 indicates good flow (Aulton, 2007; Yüksel et al., 2007). The results showed that Carr's index ranged from 9.1 to $17.3 \%$ and hence exhibited good flowability. Values for angles of repose $\leq 30^{\circ}$ generally indicate a free flowing material and $\geq 40^{\circ}$ suggest a poorly flowing material. Angle of repose was also used as an indirect method of assessing flowability of granules and the results also showed that the granules had low interparticulate friction and hence had good flowability. The results of flow rate (that is, flow under gravity) also showed that the granules had good flowability.

\section{Capsule properties}

The results of the weight uniformity of the capsules are 
Table 2. Micromeritic properties of pyridoxine hydrochloride granules.

\begin{tabular}{cccccccc}
\hline Batch & $\begin{array}{c}\text { Particle size } \\
(\boldsymbol{\mu m} \pm \mathbf{S D})\end{array}$ & $\begin{array}{c}\boldsymbol{\ell}_{\mathbf{B}} \\
(\mathbf{g} / \mathbf{m l} \pm \mathbf{S D})^{*}\end{array}$ & $\begin{array}{c}\boldsymbol{\ell}_{\boldsymbol{T}} \\
(\mathbf{g} / \mathbf{m l} \pm \mathbf{S D})^{*}\end{array}$ & $\begin{array}{c}\text { AR } \\
\left.\mathbf{(}^{\circ} \pm \mathbf{S D}\right)^{*}\end{array}$ & $\mathbf{H R}$ & $\mathbf{C l}(\%)$ & $\begin{array}{c}\text { FR } \\
(\mathbf{g} / \mathbf{s e c} \pm \mathbf{S D})\end{array}$ \\
\hline F1 & $259.0 \pm 0.1$ & $0.68 \pm 0.27$ & $0.75 \pm 0.07$ & $27.82 \pm 0.03$ & 1.10 & 9.10 & $8.62 \pm 0.05$ \\
F2 & $256.0 \pm 0.2$ & $0.61 \pm 0.23$ & $0.74 \pm 0.06$ & $29.94 \pm 0.01$ & 1.21 & 16.70 & $6.65 \pm 0.07$ \\
F3 & $245.0 \pm 0.1$ & $0.53 \pm 0.17$ & $0.63 \pm 0.12$ & $29.93 \pm 0.09$ & 1.19 & 15.80 & $5.12 \pm 0.03$ \\
F4 & $252.0 \pm 0.3$ & $0.51 \pm 0.11$ & $0.61 \pm 0.19$ & $21.80 \pm 0.11$ & 1.20 & 16.00 & $8.32 \pm 0.05$ \\
F5 & $249.0 \pm 0.2$ & $0.50 \pm 0.17$ & $0.61 \pm 0.21$ & $24.86 \pm 0.05$ & 1.22 & 17.30 & $8.61 \pm 0.07$ \\
\hline
\end{tabular}

Values shown are mean $\pm \mathrm{SD}\left({ }^{*} \mathrm{n}=3\right) ; \ell_{\mathrm{B}}$ and $\ell_{\mathrm{T}}=$ Bulk and tapped densities, $\mathrm{AR}=$ Angle of repose, $\mathrm{HR}=\mathrm{Hausner}$ 's ratio, $\mathrm{Cl}=\mathrm{Carr}$ 's compressibility index, FR = Flow rate; batches F1, F2, F3, F4 and F5 contain propylene glycol 1, 2, 3, 4 and 5 ml respectively.

Table 3. Properties of pyridoxine capsules.

\begin{tabular}{|c|c|c|c|}
\hline Batch & $\begin{array}{c}\text { Capsule weight } \\
(\mathrm{mg} \pm \mathrm{CV})^{\star}\end{array}$ & $\begin{array}{c}\text { Disintegration } \\
\text { time }(\min \pm \mathrm{SD})^{\mathrm{a}}\end{array}$ & $\begin{array}{l}\text { Drug content } \\
(\mathrm{mg} \pm \mathrm{SD})^{\mathrm{a}}\end{array}$ \\
\hline $\mathrm{F} 1$ & $253.00 \pm 0.94$ & $3.54 \pm 0.37$ & $52.50 \pm 0.13$ \\
\hline $\mathrm{F} 2$ & $260.00 \pm 1.01$ & $3.31 \pm 0.17$ & $49.00 \pm 0.27$ \\
\hline F3 & $255.00 \pm 0.92$ & $3.30 \pm 0.29$ & $49.00 \pm 0.15$ \\
\hline $\mathrm{F} 4$ & $263.00 \pm 2.64$ & $3.40 \pm 0.11$ & $50.00 \pm 0.31$ \\
\hline $\mathrm{F} 5$ & $257.00 \pm 0.81$ & $3.56 \pm 0.32$ & $53.50 \pm 0.11$ \\
\hline
\end{tabular}

*Mean for 20 capsules, ${ }^{a}$ Mean for 10 capsules, CV: coefficient of variation, SD: standard deviation, batches F1, F2, F3, F4 and F5 contain propylene glycol 1, 2, 3,4 and $5 \mathrm{ml}$, respectively, $\mathrm{P}<0.05$ was considered significant.

Table 4. Release kinetics of sustained release pyridoxine hydrochloride in SIF.

\begin{tabular}{lcccccccc}
\hline \multirow{2}{*}{ Batch } & \multicolumn{3}{c}{ Higuchi } & \multicolumn{2}{c}{ First order } & \multicolumn{3}{c}{ Ritger-Peppas } \\
\cline { 2 - 8 } & $\left(\mathbf{r}^{2}\right)$ & $\mathbf{( n )}$ & $\mathbf{K}\left(\mathbf{h}^{-1}\right)$ & $\left(\mathbf{r}^{2}\right)$ & $\mathbf{K}\left(\mathbf{h}^{-1}\right)$ & $\left(\mathbf{r}^{2}\right)$ & $(\mathbf{n})$ & $\mathbf{K}\left(\mathbf{h}^{-\mathbf{n}}\right)$ \\
\hline F1 & 0.936 & 0.097 & 69.2 & 0.867 & 1.559 & 0.953 & 0.099 & 0.81 \\
F2 & 0.937 & 0.169 & 76.7 & 0.975 & 1.687 & 0.953 & 0.173 & 1.26 \\
F3 & 0.943 & 0.230 & 65.3 & 0.878 & 1.655 & 0.998 & 0.183 & 1.34 \\
F4 & 0.958 & 0.036 & 93.3 & 0.953 & 1.002 & 0.954 & 0.040 & 1.07 \\
F5 & 0.961 & 0.048 & 64.9 & 0.750 & 1.578 & 0.866 & 0.022 & 1.08 \\
\hline
\end{tabular}

Batches F1, F2, F3, F4 and F5 contain propylene glycol 1, 2, 3, 4 and $5 \mathrm{ml}$, respectively.

shown in Table 3 . The results showed that all the capsules complied with requirement for capsule weight uniformity (BP, 2009) and the percentage deviations obtained from the capsule weight uniformity test were significantly below $5 \%$. The results of the disintegration time of the capsules showed that they disintegrated within 3.31 to $3.56 \mathrm{~min}$, and hence did not vary significantly within the batches $(P<0.05)$. This may be due to the kind of capsule shell used. The product being a modified release product, one would ordinarily expect prolonged disintegration time, but the granules were not encapsulated with gastro-resistant capsules. Therefore, the capsule shell was not the cause of the sustained release and was not designed as such. The results of the drug content of the capsules also showed that pyridoxine hydrochloride capsules had high percentage drug content and complied with BP standards for drug content. The results showed that the drug content were within 90 to $110 \%$ of the average values specified in the official book (BP, 2009) as shown in Table 3.

\section{In vitro drug release}

The results of the in vitro drug release are shown in Figure 1a to $\mathrm{c}$. From the results of the in vitro release of pyridoxine hydrochloride capsules in $0.1 \mathrm{~N} \mathrm{HCl}$ (Figure $1 \mathrm{a})$, the results showed an initial high release of drug between 0.5 and $2 \mathrm{~h}$ before maintaining the sustained drug release over time between 2 and $3 \mathrm{~h}$. Batch F1 containing 


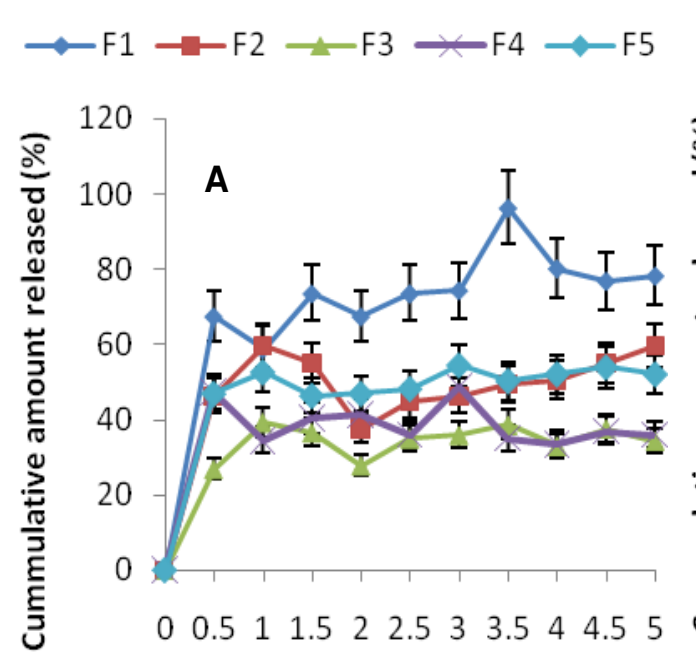

Time (h)
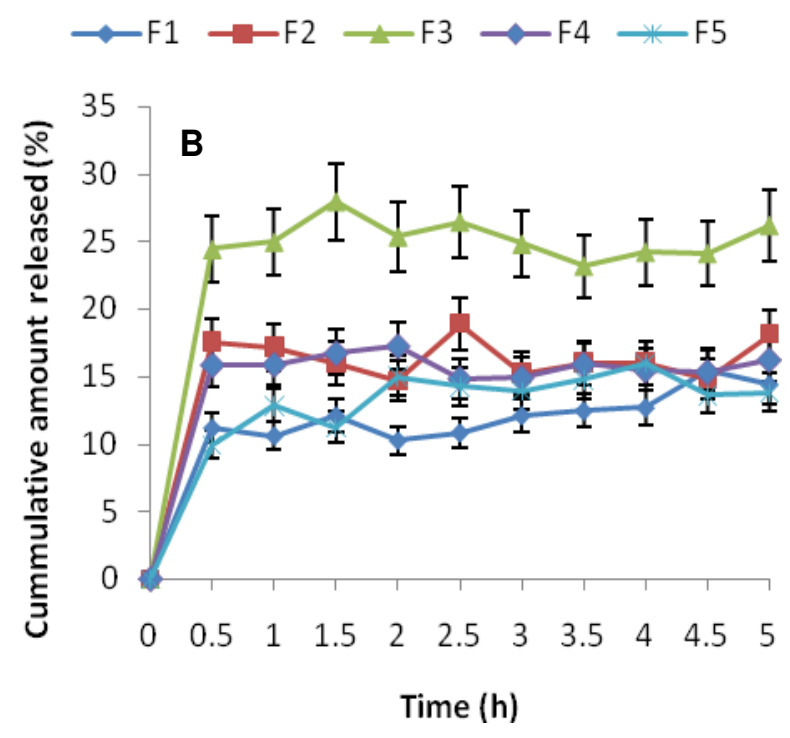

Time (h)

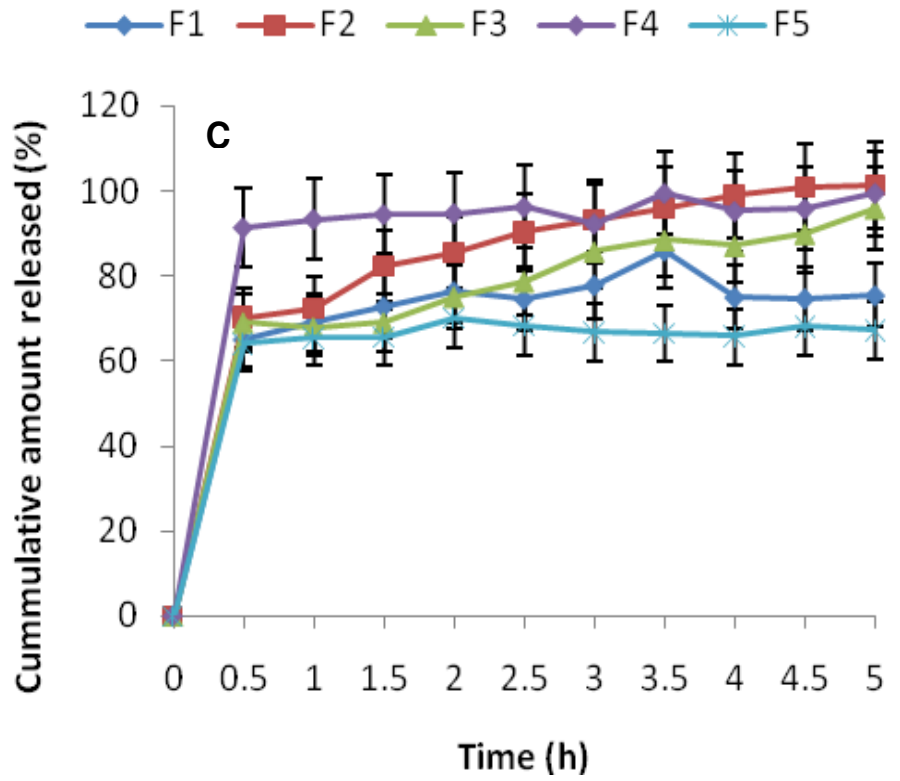

Figure 1. Release profile of pyridoxine hydrochloride in (A) $0.1 \mathrm{~N} \mathrm{HCl}$, (B) SGF (pH 1.2), and (C) SIF (pH 7.2). Batches F1, F2, F3, F4 and F5 contain propylene glycol 1, 2, 3, 4 and $5 \mathrm{ml}$, respectively.

$1 \mathrm{ml}$ of propylene glycol had $96 \%$ drug release at $3.5 \mathrm{~h}$, however, $\mathrm{T}_{100 \%}$ could not be attained in other formulations. Increase in the amount of propylene glycol significantly $(P<0.05)$ delayed the release of pyridoxine hydrochloride as shown in Figure 1 a to $\mathrm{C}$. The results of in vitro drug release in SGF $(\mathrm{pH}, 1.2)$ showed that the release of pyridoxine hydrochloride was significantly $(\mathrm{P}<$ $0.05)$ lower than the release in $0.1 \mathrm{~N} \mathrm{HCl}$ and in SIF $(\mathrm{pH}$, 7.2), respectively. Generally, batch F5 formulated with 5 $\mathrm{ml}$ of propylene glycol had 46.87 and $54.42 \%$ drug release at $T_{120}$ and $T_{180}$ (120 and $180 \mathrm{~min}$ ), respectively in $0.1 \mathrm{~N} \mathrm{HCl}$, also $\mathrm{F} 5$ had 15.04 and $13.96 \%$ drug release at $\mathrm{T}_{120}$ and $\mathrm{T}_{180}$, respectively in SGF $(\mathrm{pH}, 1.2)$ and 69.87 and
$66.6 \%$ drug release at $\mathrm{T}_{120}$ and $\mathrm{T}_{180}$, respectively in SIF $(\mathrm{pH}, 7.2)$. Therefore, pyridoxine hydrochloride sustained release capsule formulated exhibited higher drug release in SIF (pH, 7.2).

\section{In vitro release kinetics}

From the results of drug release kinetics shown in Table 4 , the regression coefficients had $r^{2}$ of $\approx 0.9$. Also, the release exponent in the Ritger-Peppas model (n) for all the batches suggested that the mechanism that led to the release of pyridoxine hydrochloride from the capsule was 
by diffusion with release rate adequate for a sustained release dosage form. Higuchi's kinetics seconds the Ritger-Peppas in the linearity of their plot with $r^{2}$ of $\approx 0.9$. The linearity of Higuchi's kinetic explains why the drug diffuses at a comparatively slower rate as the distance for diffusion increases, which is referred to as square root kinetics (or Higuchi's kinetics) (Rawat et al., 2011; Singh et al., 2011). The linearity of the plot indicates that the release of pyridoxine hydrochloride from the samples followed diffusion mechanism. The results of first order kinetics showed that drug release was not dissolution controlled $\left(r^{2} \neq 0.9\right)$ in most of the formulations, however, batches F2 and F4 showed some level of linearity $\left(r^{2}=\right.$ $0.9)$. This suggested that the release of drug from these batches followed mixed mechanism of drug release (Rawat et al., 2011; Singh et al., 2011).

\section{Conclusion}

Pyridoxine hydrochloride sustained release capsules with fixed concentrations of binder-disintegrants, diluents and equal load of active pharmaceutical ingredient were successfully formulated using propylene glycol co-solvent as the moistening agent. The results showed that free flowing spherical particles were produced. The capsules complied with BP (2009) specifications for capsule weight uniformity and drug content. The in vitro release properties of the pyridoxine capsules showed that increase in the amount of propylene glycol increased the time of drug release. Therefore, pyridoxine hydrochloride sustained release capsules could be formulated with kaolin as the diluent and propylene glycol co-solvent as the moistening agent in order to reduce the frequency of administration of this drug and improve patient compliance.

\section{REFERENCES}

Ansel HC, Allen Jr LV, Poporich NG (2007). Powders and granules. Ansel's Pharmaceutical Dosage forms and Drug Delivery Systems. $8^{\text {th }}$ Edn., Lippincott Williams and Wilkins, New Delhi, pp: 189.

Aulton ME (2007). Pharmaceutics; The Science of Dosage Form Design, $3^{\text {rd }}$ Edn. Churchill Living Stone, Edinburgh. pp. 483-499.

British Pharmacopoeia (2009). The Commission Office London. Vol. III: 6578-6585.

Chime SA, Attama AA, Agubata CO, Ogbonna JD, Onunkwo GC (2012). Micromeritic and antinociceptive properties of lyophilized indomethacin-loaded SLMs based on solidified reverse micellar solutions. J. Pharm. Res. 5(6):3410-3416.

Fukumori Y, Ichikawa H (2002). Fluid Bed Processes for Forming Functional Particles. In: James Swarbrick, James C, Boylan (Eds), Encyclopedia of Pharmaceutical Technology, $2^{\text {nd }}$ ed., Vol 3. Marcel Dekker Inc., New York. pp. 1392-1400.

Jia Y, Joly H, Omri H (2008). Liposomes as a carrier for gentamicin delivery: Development and evaluation of the physicochemical properties. Int. J. Pharm. 359:254-263.
Kim JK, Park JS, Kim CK (2010). Development of a binary lipid nanoparticles formulation of itraconzole for parenteral administration and controlled release. Int. J. Pharm. 383:209-215.

Lachman L, Herbert A, Liberman J (1990). In: The theory and practice of Industrial Pharmacy. Varghese publishing House, Hind Rajasthan Building Dadar Mumbai 400001, 3rd Edn. P 318.

Mathew ST, Devi SG (2007). Formulation and evaluation of ketorolac tromethamine-loaded albumin microspheres for potential intramuscular administration. AAPS Pharm. Sci. Tech. 8(1):34-43.

Ngwuluka NC, Idiakhoa BA, Nep El, Ogaji I, Okafor SI (2010). Formulation and evaluation of paracetamol tablets manufactured using the dried fruit of Phoenix dactylifera Linn as an excipient. Res. Pharm. Biotech. 2(3):25-32.

Ofoefule SI, Chukwu A (2002). Sustained release dosage forms: design and evaluation of oral products. In: Ofoefule S.I (ed.), Text Book of Pharmaceutical Technology and Industrial Pharmacy. Samakin (Nig.) Enterprises, Lagos. 94-120.

Okoye EI, Onyekweli AO, Fatoki OO (2012). Evaluation of LD50 of Cashew Gum and the Comparative Study of its Functionality in Cotrimoxazole Granule and Tablet Formulations. Br. J. Pharm. Toxicol. 3(4):156-164.

Ravi-Kumar MNV (2000). Nano and microparticles as controlled drug delivery devices. J. Pharm. Pharm. Sci. 3:234-58.

Rawat SM, Singh D, Saraf S (2011). Formulation optimization of controlled delivery systems for antihypertensive peptides using response surface methodology. Am. J. Drug Dis. Dev. 1(3):174-187.

Rhee YS, Park CW, Nam TY, Shin YS, Chic SC, Park ES (2007). Formulation of parenteral emulsion containing itraconazole. Arch Pharm. Res. 30:114-23.

Ritger PL, Peppas NA (1987a). A simple equation for description of solute release 1. Fickian and non- Fickian release from non swellable device in the form of slabs, spheres, cylinders and discs. J. Cont. Rel. 5:23-36

Ritger PL, Peppas NA (1987b). A simple equation for description of solute release II. Fickian and anomalous release from swellable devices. J. Cont. Rel. 5: 37-42

Sean CS ed (2011). Martindale: The Complete Drug Reference, $\left(36^{\text {th }}\right.$ Edn). London: Pharmaceutical Press. ISBN 978085369840 1:289291.

Singh J, Gupta S, Kaur H (2011). Prediction of in vitro drug release mechanisms from extended release matrix tablet using SSR/SR ${ }^{2}$ techniques. Trends App. Sci. Res. 6(4):400-409.

Sinko PJ (2006). Martins Physical Pharmacy and Pharmaceutical Sciences; Physical, Chemical and Biopharmaceutical Principles in Pharmaceutical Sciences, $\left(6^{\text {th }}\right.$ Edn. $)$. Lippincott Williams and Wilkins, USA. $665-669$.

Umeyor EC, Kenechukwu FC, Ogbonna JD, Chime SA, Attama AA (2012). Preparation of novel solid lipid microparticles loaded with gentamicin and its evaluation in vitro and in vivo. J. Microencapsul. 112. DOI: $10.3109 / 02652048.2011 .651495$.

Welling PG (2002). Absorption of drugs. In: James Swarbrick, James C, Boylan (Eds), Encyclopedia of Pharmaceutical Technology, $2^{\text {nd }}$ ed., Vol 3; Marcel Dekker Inc., New York. 3606:1-21.

Wissing SA, Kayser O, Müller RH (2004). Solid lipid nanoparticles for parenteral drug delivery. Adv. Drug Deliv. Rev. 56(9):1257-72.

Yüksel N, Türkmen B, Kurdoğlu AH, Başaran B, Erkin J, Baykara T (2007). Lubricant efficiency of magnesium stearate in direct compressible powder mixtures comprising cellactose ${ }^{\circledR} 80$ and pyridoxine hydrochloride. FABAD J. Pharm. Sci. 32:173-183. 